\title{
Which medical error to disclose to patients and by whom? Public preference and perceptions of norm and current practice
}

\author{
Muhammad M Hammami", Sahar Attalah, Mohammad Al Qadire
}

\begin{abstract}
Background: Disclosure of near miss medical error (ME) and who should disclose ME to patients continue to be controversial. Further, available recommendations on disclosure of ME have emerged largely in Western culture; their suitability to Islamic/Arabic culture is not known.

Methods: We surveyed 902 individuals attending the outpatient's clinics of a tertiary care hospital in Saudi Arabia. Personal preference and perceptions of norm and current practice regarding which ME to be disclosed (5 options: don't disclose; disclose if associated with major, moderate, or minor harm; disclose near miss) and by whom (6 options: any employee, any physician, at-fault-physician, manager of at-fault-physician, medical director, or chief executive director) were explored.
\end{abstract}

Results: Mean (SD) age of respondents was 33.9 (10) year, 47\% were males, 90\% Saudis, 37\% patients, 49\% employed, and $61 \%$ with college or higher education. The percentage ( $95 \%$ confidence interval) of respondents who preferred to be informed of harmful ME, of near miss ME, or by at-fault physician were $60.0 \%$ (56.8 to 63.2), $35.5 \%$ (32.4 to 38.6), and 59.7\% (56.5 to 63.0), respectively. Respectively, $68.2 \%$ (65.2 to 71.2 ) and $17.3 \%$ (14.7 to 19.8) believed that as currently practiced, harmful ME and near miss ME are disclosed, and 34.0\% (30.7 to 37.4) that ME are disclosed by at-fault-physician. Distributions of perception of norm and preference were similar but significantly different from the distribution of perception of current practice $(P<0.001)$. In a forward stepwise regression analysis, older age, female gender, and being healthy predicted preference of disclosure of near miss $\mathrm{ME}$, while younger age and male gender predicted preference of no-disclosure of ME. Female gender also predicted preferring disclosure by the at-fault-physician.

Conclusions: We conclude that: 1) there is a considerable diversity in preferences and perceptions of norm and current practice among respondents regarding which ME to be disclosed and by whom, 2) Distributions of preference and perception of norm were similar but significantly different from the distribution of perception of current practice, 3) most respondents preferred to be informed of ME and by at-fault physician, and 4) one third of respondents preferred to be informed of near-miss ME, with a higher percentage among females, older, and healthy individuals.

\section{Background}

In healthcare, it is not uncommon that patients are exposed to risks of harm. Some risks are predictable, at least at statistical level, and an informed consent is obtained. Other risks, such as those occurring because of medical errors (ME) are in a sense unpredictable and

\footnotetext{
* Correspondence: muhammad@kfshrc.edu.sa

Centre for Clinical Studies and Empirical Ethics King Faisal Specialist Hospital and Research Centre Riyadh, Saudi Arabia
}

an informed consent can not be obtained. An ME is defined as an act or omission that would have been judged wrong by knowledgeable peers at the time it occurred [1]. Some ME may not materialize into harm; a near miss is an event that under slightly different circumstances could have been an accident, either because the error was detected and corrected in time or because the patient was just lucky [2]. When an ME occurs, two actions should be considered: reporting it to the healthcare system (and through it to potential future patients) 
and disclosing it to the patient involved. Reporting ME is paramount for quality and safety improvement and should include near miss ME [1,3]; compared to reporting harmful ME, reporting near miss $\mathrm{ME}$ offers greater frequency and fewer barriers to data collection [3].

Full disclosure of ME includes an explicit statement that an error (rather than just a "complication") occurred, basic description of the error, who committed the error, why it did happen, how recurrences will be prevented, and an apology [4,5]. Non disclosure of harmful ME is considered a violation of ethical principles from both deontological and consequentialist perspectives [6]. A policy of open disclosure standard that demands disclosure of critical events by the provider or the institution [7] was promulgated in 2001 by the Joint Commission on Accreditation of Healthcare Organizations (JCAHO) and is now reflected in similar initiatives in the UK, Canada, and Australia [8-12]. These regulations and theoretical ethical considerations are consistent with the results of empirical ethics studies in Western cultures showing that patients overwhelmingly desire full disclosure of harmful ME [5,13-17] and that full disclosure is likely to have a positive or no effect on how patients respond to ME [18].

Disclosure of near miss ME to patients is a matter of controversy $[19,20]$ and an issue on which current guidelines are silent. Disclosure is recommended by some [21-24] but not all authors in the field [2,25]. The American Society for Reproductive Medicine states that if there is clearly no adverse effect of a ME, disclosure may not be obligatory if it may unnecessarily increase patient's stress [26]. In the few empirical studies that have specifically addressed near miss ME, $88 \%$ to $92 \%$ of patients desired disclosure [15,27]. In contrast, most physicians opposed near miss ME disclosure [5]. Determining who should disclose ME is another matter of controversy. According to Liang model [21] and the policy described by Kraman and colleagues [28], risk management committee should be responsible for disclosure. Others believe that the responsibility for disclosure belongs to the physician $[10,11,22,29]$. JCAHO standard requires that a responsible licensed independent practitioner or his/her designee explains the outcome [7].

Current disclosure literature contains important but unanswered questions such as how patient' preferences for disclosure vary along cultural and other dimensions $[10,11]$. An individual's ethical decision-making is based on his/her values and beliefs. Although major ethical values are rather universal, ethical values are subject to individual interpretation and people naturally differ in their values' hierarchy and in their beliefs. Autonomy is placed at the top of the "moral mountain" and is given a "place of honor" in Western but not other ethics [30].
Further, there are several meanings of autonomy along a spectrum from a negative or anti paternalistic model to a positive mandating model [31]. Furthermore, it has been argued that respect should be for the person rather than purely for autonomy [31,32]; trust in providers, treatment with respect, and dignity were more closely associated with patients overall evaluation of their hospitals than adequate involvement in decision-making [33]. To our knowledge, there is no study on patients' views on disclosure of ME that has been conducted in Arabic/ Islamic countries or that compared preference (a statement about the person who has the preference) and perception of norm (a statement about the thing which is being judged).

The aim of this study was to obtain empirical evidence on public views on disclosure of ME in the outpatient's setting at a tertiary care hospital in Saudi Arabia. We examined preference, perception of norm, and perception of current practice on two topics, which ME to be disclosed and who to disclose ME.

\section{Methods}

This cross sectional survey was conducted in accordance with the ethical principles contained in the Declaration of Helsinki and after approval of the Research Ethics Committee of the King Faisal Specialist Hospital and Research Center (KFSH\&RC) in the period from November 2007 to March 2009. All respondents gave verbal consent.

Two sets of three questionnaires addressing personal preference, perception of norm (what is appropriate in general/should be done), and perception of current practice at KFSH\&RC regarding which medical error is disclosed to patients (set one) and by whom (set two) were developed by the authors in Arabic language based on literature review. After initial development, the questionnaires were presented for comments to 6 physicians and revised accordingly (minor changes in language usage to have consistency throughout the questionnaires). Face validity was assessed by interviewing 10 respondents after completing the questionnaires. The final version was pilot tested on 10 other individuals for clarity and stability (2-3 days) and found suitable. An English translation (accuracy confirmed by back translation) of the two questionnaires on personal preference is shown in Table 1. Similar statements with appropriate modifications were used for the questionnaires on perceptions of norm and current practice. For example, we used the phrase "I prefer" combined with "to be" and "my/me" to indicate personal preference and "I think" combined with "should be" and "patient/his" to indicate perception of norm. For perception of current practice questionnaires, "I prefer" was omitted and "is" was combined with "patient/his". The statements in each questionnaire were arranged 


\section{Table 1 Questionnaires on Personal Preference of Which Medical Error to be Disclosed and Who to Disclose it}

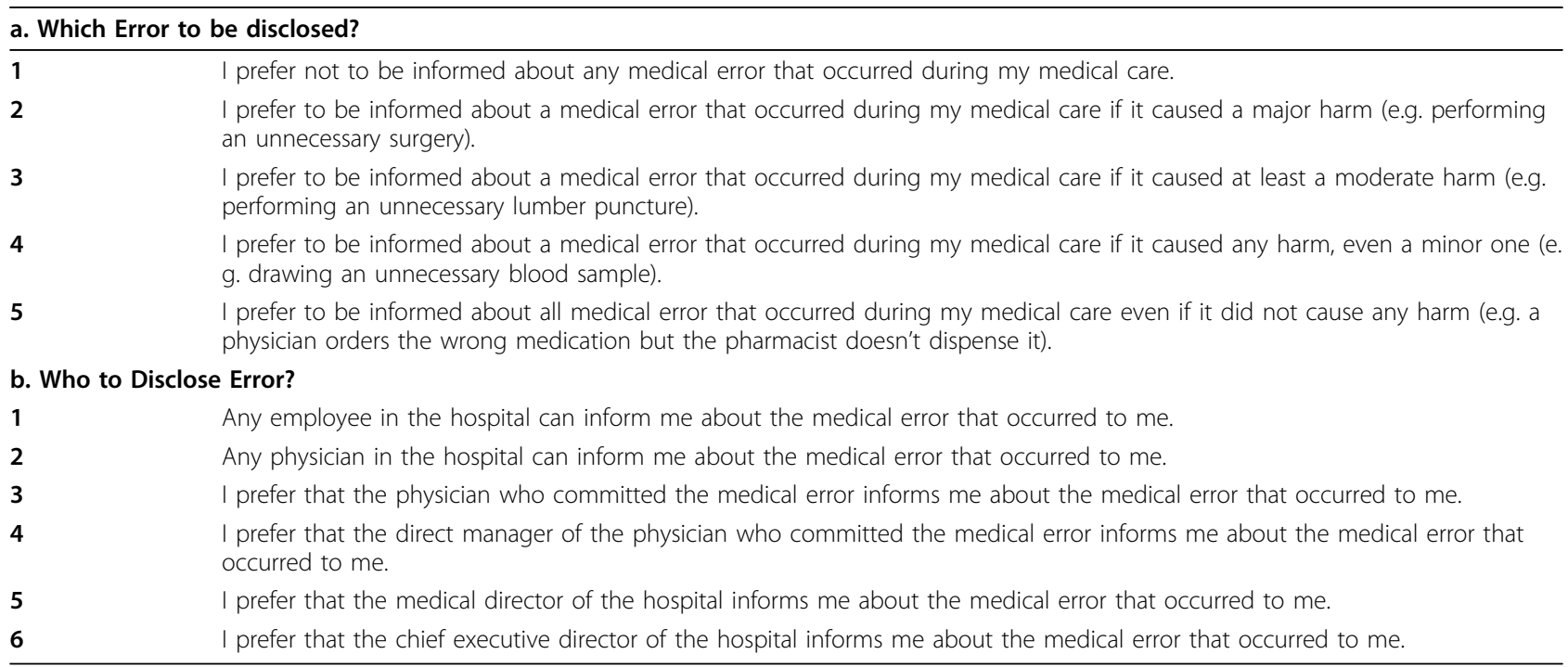

from least to most demanding. Before completing the questionnaires, participants were given the following introductory information on medical errors: "Clinical practice, just like any other beneficial practice, could hardly be completely free from harm. Such harm can be divided into two types: 1) harm that can be predicted and thus can be avoided, e.g. anaphylactic shock caused by penicillin administration to a person known to have penicillin allergy, and 2) harm that can't be predicted/avoided, e.g. inflammation of the bowel after some antibiotics treatment. The first type is called medical error. A medical error is defined as failure to complete a planned medical action as intended, or the use of a wrong plan to achieve an aim. Medical errors may or may not cause harm, for example, penicillin could be wrongly prescribed by a physician but not given to the patient because the error is discovered and corrected in time by a pharmacist or nurse. Physicians may not disclose medical errors to patients for a variety of reasons that are related to patient's interests or physician's interests or because they may think it is useless to do so. Similarly, some patients wish to be informed about medical errors and some do not. Disclosing medical errors to patients is an issue separate from disclosing them to hospital administration. In this study we are interested in disclosing medical errors to patients. We would like to know your views on: 1) which medical error to be disclosed to patients, and 2) who to disclose medical errors to patients. There are three groups of statements for each of these two questions. The first is on what you personally prefer, the second is on what you think is best in general, and the last is on what you think reflect the current practice at KFSH\&RC". For each questionnaire, participants were asked to choose the most representative statement. The six questionnaires are available in Additional file 1.

Eligibility criteria included age $\geq 18$ years, ability to understand the study and provide verbal consent, and being an Arab (having nationality of one of the Arab League States). 1069 individuals in waiting areas of the outpatient clinics of KFSH\&RC were invited to participate in the study. The number of individuals invited from each area was prorated based on average clinic load. The questionnaires were self or investigator administered in Arabic, according to respondent's reported educational level ( $\geq$ college education) and expressed need for assistance.

The response rate was calculated as the number of usable questionnaires (902) divided by the number of individuals approached. Data were verified by double entry. The number (\% and $95 \%$ confidence interval) of respondents who chose each of the statements was determined. We used $\mathrm{Chi}^{2}$ test to examine the null hypothesis of random distribution of statements' choice for each questionnaire and Kendall's W test to compare the distribution of statements' choice among the three questionnaires in each set followed by pair wise comparison by Wilcoxon Signed Ranks test. We used the Mann-Whitney test to examine if responses differed according to gender, nationality, or health status (having a chronic illness or healthy), and the Kruskal-Wallis test to examine if they differed according to education level (illiterate, school, $\geq$ college). Correlation between age and responses to each of the three questionnaires on which ME to be disclosed was studied using Spearman's test.

We dichotomized responses to the questionnaires on which ME to be disclosed as statement one (don't disclose ME) vs. other statements, and statement 5 
(disclose near miss ME) vs. other statements; and to the questionnaires on who to disclose ME as statement three (at-fault-physician) vs. other statements. The association with gender, nationality, or health status was studied using Mantel-Haenszel common odds ratio estimate. The $t$ test was used to compare mean age. The association between five demographic variables (age, gender, nationality, health status, and educational level) and the dichotomously coded variables was modeled using forward stepwise logistic regression analysis; the odds ratios and 95\% confidence intervals were estimated. Model-based means and percentages were determined by setting other variables in the model to their mean values. Analyses were conducted by one of the author $(\mathrm{MMH})$ with SPSS for Windows software (release 17.0.0, 2008. SPSS Inc., Chicago, ILL, USA). 2-tailed $\mathrm{P}$ values are reported.

\section{Results}

1069 individuals were approached; 63 refused to participate, 14 did not understand the study, and 90 did not complete the questionnaires. Thus responses from 902 (84\%) individuals were available for analysis. The demographics of respondents are shown in Table 2.

Which medical error to disclose to patients?

As shown in Table 3, 60.0\% (95\% confidence interval, $56.8 \%$ to $63.2 \%$ ) of respondents preferred to be informed

Table 2 Characteristics of Study Participants (no. = 902)

\begin{tabular}{|c|c|}
\hline Age-mean (SD), yr & $33.9(10)$ \\
\hline \multicolumn{2}{|l|}{ Gender-no. (\%) } \\
\hline Male & $425(47)$ \\
\hline Female & $477(53)$ \\
\hline \multicolumn{2}{|l|}{ Nationality-no. (\%) } \\
\hline Saudi & $810(90)$ \\
\hline Non-Saudi Arabs* & $92(10)$ \\
\hline \multicolumn{2}{|l|}{ Education Level-no. (\%) } \\
\hline Illiterate & $46(5)$ \\
\hline Primary School & $30(3)$ \\
\hline Intermediate School & $75(8)$ \\
\hline Secondary School & $199(22)$ \\
\hline College & $159(18)$ \\
\hline University & $392(43)$ \\
\hline \multicolumn{2}{|l|}{ Occupation-no. (\%) } \\
\hline Employed & $438(49)$ \\
\hline Student & $142(16)$ \\
\hline Housewife & $267(30)$ \\
\hline Unemployed & $54(6)$ \\
\hline \multicolumn{2}{|l|}{ Chronic Illness-no. (\%) } \\
\hline Present & $333(37)$ \\
\hline Not present & $569(63)$ \\
\hline
\end{tabular}

*Egyptian, Syrian, Lebanese, Yemeni, Sudanese. of harmful (major, moderate, or minor) ME. In addition, $35.5 \%$ (32.4\% to $38.6 \%$ ) preferred to be informed of near miss ME. Only $4.5 \%$ (3.2\% to $5.9 \%$ ) preferred not to be informed of ME. The distribution of norm perception was not statistically different from the distribution of preference $(\mathrm{P}=0.15)$. Further, there was significant correlation between the distributions of preference and norm perception (rho 0.64, $\mathrm{P}<0.001$ ).

\section{Who should disclose medical error to patients?}

As shown in Table 4, 59.7\% (56.5\% to 63.0\%) of respondents preferred to be informed of ME by at-fault-physician. The distribution of the norm perception was not statistically different from the distribution of preference $(\mathrm{P}=0.33)$.

\section{Is there a difference between perceptions of norms and current practice?}

There was significant difference $(\mathrm{P}<0.001)$ between the distributions of norm perception and current practice perception in regard to which ME to be disclosed (Table 3). The distribution of current practice perception was relatively shifted to the left (i.e., less demanding). While only $2.9 \%$ ( $1.8 \%$ to $4.0 \%)$ perceived it as norm not to be informed of ME, $14.7 \%$ (12.3\% to $17.0 \%)$ perceived that this is currently practiced. In contrast, while $30.4 \%$ (27.4\% to $33.4 \%)$ perceived it as norm to be informed of near miss ME, only $17.3 \%$ (14.7\% to $19.8 \%$ ) perceived that this is currently practiced. Nevertheless, there was significant correlation between norm perception and current practice perception (rho 0.17, $\mathrm{P}<$ 0.001).

There was also significant $(\mathrm{P}<0.001)$ difference between the distributions of norm perception and current practice perception regarding who to disclose $\mathrm{ME}$ (Table 4). The distribution of current practice perception was relatively shifted to the left (i.e., less demanding). $57.2 \%$ (53.9\% to $60.5 \%)$ perceived it as norm to be informed of ME by at-fault-physician but only $34.0 \%$ (30.7 to $37.4 \%$ ) perceived that this is currently practiced.

\section{Association between responses and respondents' demographics}

As shown in Tables 5 and 6, gender was significantly associated with preference and with current practice perception. The odds ratio (OR) of male/female was 0.45 (0.34 to 0.60$)$ for preference of disclosure of near miss $\mathrm{ME}, 4.23$ (2.00 to 8.98) for preference of no-disclosure of ME, 0.40 ( 0.30 to 0.52$)$ for disclosure of ME by atfault-physician, 0.38 (0.25 to 0.57$)$ for current practice perception that ME are not disclosed, and 0.45 (0.33 to 0.61 ) for current practice perception that ME are disclosed by at-fault-physician. Thus compared to males, a higher percentage of females preferred disclosure by at- 
Table 3 Which Medical Error to be Disclosed to Patients According to Personal Preference and Perceptions of Norm and Current Practice

\begin{tabular}{lccccc}
\hline & & \multicolumn{4}{c}{ Disclose medical error if there is } \\
\cline { 2 - 6 } & Don't disclose & Major harm & Moderate harm & Minor harm & Near miss \\
\hline Preference [902] & $41(4.5)$ & $193(21.4)$ & $143(15.9)$ & $205(22.7)$ & $320(35.5)$ \\
Perception of Norm [902] & $26(2.9)$ & $189(21.0)$ & $193(21.4)$ & $220(24.4)$ & $274(30.4)$ \\
Perception of Practice [846] & $124(14.7)$ & $250(29.6)$ & $185(21.9)$ & $141(16.7)$ & $146(17.3)$ \\
\hline
\end{tabular}

"Don't disclose", and disclose when there is a "major harm", "moderate harm", "minor harm", or "near miss" correspond, respectively, to statements 1 to 5 in Table 1(a). Numbers between [.] represent the number of responses. Data indicate the number (\%) of respondents who chose the corresponding statement. Chi square test for the null hypothesis of random distribution was significant $(P<0.001)$ for each of the three questionnaires. Kendall's $W$ coefficient of concordance (comparing the choices in the 3 questionnaires) was $0.089(P<0.001)$. Wilcoxon signed ranks test: preference vs. perception of norm, $P=0.15$; preference vs. perception of current practice, $\mathrm{p}<0.001$; perception of norm vs. perception of current practice, $\mathrm{P}<0.001$.

fault-physician (70\% vs. 48\%), disclosure of near miss ME ( $44 \%$ vs. $26 \%$ ), and a smaller percentage preferred no-disclosure of ME ( $2 \%$ vs. $8 \%$ ). This difference between females and males in preference was consistent with their current practice perception that at-fault-physician discloses ME (43\% vs. $26 \%$ ) but not with which ME to be disclosed (17\% vs. $17 \%$ for near miss ME, $20 \%$ vs. $9 \%$ for no-disclosure of ME); thus females had a larger gap between preference and current practice perception regarding which $\mathrm{ME}$ to be disclosed.

Nationality (Saudis vs. Non-Saudi Arabs) was not significantly associated with preference or perception. Health status was significantly associated with preference of which ME to be disclosed. The OR (patient to healthy) was 0.74 (0.56 to 0.99 ) for preference of disclosure of near miss ME and 0.40 (0.18 to 0.88 ) for preference of no-disclosure of $\mathrm{ME}$, although the overall distributions of preferences were not statistically different Thus patients were less likely than healthy individuals to prefer the more extreme choices. Current practice perceptions of patients and healthy individuals were not statistically different (Table 5 \&6).

Education was significantly associated with preference and current practice perception of disclosure of ME. A higher percentage of illiterates preferred to be informed of near miss $\mathrm{ME}$ and perceived that in current practice ME are not disclosed. The OR of school graduates and $\geq$ college graduates to illiterates was
0.41 (0.22 to 0.77$)$ and $0.40(0.21$ to 0.73$)$, respectively, for preference of disclosure of near miss $\mathrm{ME}$ and 0.50 (0.23 to 1.12 ) and 0.31 ( 0.17 to 0.78 ) for the perception that under current practice $\mathrm{ME}$ are not disclosed (Table 5). Twenty nine percent of the illiterates, $17 \%$ of school graduates, and $13 \%$ of $\geq$ college graduates perceived that current practice doesn't disclose ME, whereas $2 \%, 6 \%$, and $4 \%$, respectively, preferred such practice, indicating a larger gap between preference and perception of current practice with lower education level (Table 5).

Age was significantly associated with preference. Individuals who preferred to be informed of near miss $\mathrm{ME}$ or who preferred to be informed by at-fault-physician were older than the rest with a mean (95\% confidence interval) difference of $1.60(0.23$ to 2.30$)$ year $(\mathrm{P}=0.02)$ and $1.65(0.29$ to 3.01$)$ year $(\mathrm{P}=0.02)$, respectively, whereas individuals who preferred not to be informed of ME were younger with a mean difference of $4.36(1.22$ to 7.51$)$ year $(P=0.007)$. There was no significant association between age and current practice perception regarding disclosure of near miss $\mathrm{ME}$, no-disclosure of $\mathrm{ME}$, or disclosure by at-fault-physician ( $\mathrm{P}=0.83, \mathrm{P}=$ $0.19, \mathrm{P}=0.76$, respectively, for mean age difference). Further, age correlated positively with preference score (statement number, 1 to 5 ) of which ME to be disclosed (rho $0.11, \mathrm{P}=0.001$ ) but not with current practice score (rho $-0.03, \mathrm{P}=0.45)$.

Table 4 Who to Disclose Medical Error to Patients According to Personal Preference and Perceptions of Norm and Current Practice

\begin{tabular}{lcccccc}
\hline & $\begin{array}{c}\text { Any } \\
\text { employee }\end{array}$ & $\begin{array}{c}\text { Any } \\
\text { physician }\end{array}$ & $\begin{array}{c}\text { At-fault- } \\
\text { physician }\end{array}$ & $\begin{array}{c}\text { Manager of at-fault- } \\
\text { physician }\end{array}$ & $\begin{array}{c}\text { Medical } \\
\text { director }\end{array}$ & $\begin{array}{c}\text { Chief executive } \\
\text { director }\end{array}$ \\
\hline $\begin{array}{l}\text { Preference [867] } \\
\text { Perception of Norm }\end{array}$ & $16(1.8)$ & $105(12.1)$ & $518(59.7)$ & $133(15.3)$ & $54(6.2)$ & $41(4.7)$ \\
$\begin{array}{l}\text { [878] } \\
\begin{array}{l}\text { Perception of Practice } \\
\text { [758] }\end{array}\end{array}$ & $25(2.8)$ & $120(13.7)$ & $502(57.2)$ & $147(16.7)$ & $46(5.2)$ & $38(4.3)$ \\
\end{tabular}

"Any employee", "any physician", "at-fault-physician", "manager of at-fault-physician", "medical director", and "chief executive director" correspond, respectively, to statements 1 to 6 in Table 1(b). Numbers between [.] represent the number of responses. Data indicate the number (\%) of respondents who chose the corresponding statement. Chi square test for the null hypothesis of random distribution was significant $(P<0.001)$ for each of the three questionnaires. Kendall's $W$ coefficient of concordance (comparing the choices in the 3 questionnaires) was $0.075(P<0.001)$. Wilcoxon signed ranks test: preference vs. perception of norm, $\mathrm{P}=0.33$; preference vs. perception of current practice, $\mathrm{p}<0.001$; perception of norm vs. perception of current practice, $\mathrm{P}<0.001$. 
Table 5 Medical Error (ME) to be Disclosed According to Preference and Perception of Current Practice per Demographic Characteristics

\begin{tabular}{|c|c|c|c|c|c|c|c|c|c|c|}
\hline & \multicolumn{5}{|c|}{ Statement* } & \multirow[t]{2}{*}{$\begin{array}{l}\text { Overall P } \\
\text { value }^{\mathrm{a}}\end{array}$} & \multicolumn{2}{|c|}{$\begin{array}{l}\text { Disclose near } \\
\text { miss ME vs. } \\
\text { other choices }^{\text {b }}\end{array}$} & \multicolumn{2}{|c|}{$\begin{array}{c}\text { Don't disclose } \\
\text { ME } \\
\text { vs. other choices } \\
b\end{array}$} \\
\hline & $\begin{array}{l}\text { Don't } \\
\text { disclose ME }\end{array}$ & $\begin{array}{l}\text { Disclose major } \\
\text { harm ME }\end{array}$ & $\begin{array}{l}\text { Disclose } \\
\text { moderate } \\
\text { harm ME }\end{array}$ & $\begin{array}{l}\text { Disclose } \\
\text { minor } \\
\text { harm ME }\end{array}$ & $\begin{array}{l}\text { Disclose } \\
\text { near } \\
\text { miss } \\
\text { ME }\end{array}$ & & $P$ & $\begin{array}{c}\mathrm{OR} \\
(95 \% \mathrm{Cl})\end{array}$ & $P$ & $\begin{array}{c}\mathrm{OR} \\
(95 \% \mathrm{Cl})\end{array}$ \\
\hline \multicolumn{11}{|l|}{ Personal Preference } \\
\hline Males [425] & $32(8)$ & $74(17)$ & $87(21)$ & $121(29)$ & $111(26)$ & $<0.001$ & $\begin{array}{c}< \\
0.001\end{array}$ & 0.45 & $\begin{array}{c}< \\
0.001\end{array}$ & 4.23 \\
\hline Females** [477] & $9(2)$ & $119(25)$ & $56(12)$ & $84(18)$ & $209(44)$ & & & $(0.34-0.60)$ & & $(2.00-8.98)$ \\
\hline Saudis [810] & $38(5)$ & $182(23)$ & $129(16)$ & $176(22)$ & $285(35)$ & 0.06 & 0.59 & 0.88 & 0.54 & 1.46 \\
\hline Non-Saudi Arabs** [92] & $3(3)$ & $11(12)$ & $14(15)$ & $29(32)$ & $35(38)$ & & & $(0.57-1.4)$ & & $(0.44-4.83)$ \\
\hline Patients [333] & $8(2)$ & $80(24)$ & $57(17)$ & $84(25)$ & $104(31)$ & 0.25 & 0.04 & 0.74 & 0.02 & 0.40 \\
\hline Healthy** [569] & $33(6)$ & $113(20)$ & $86(15)$ & $121(21)$ & $216(38)$ & & & $(0.56-0.99)$ & & $(0.18-0.88)$ \\
\hline$\geq$ College, 551 & $21(4)$ & $114(21)$ & $101(18)$ & $128(23)$ & $187(34)$ & 0.02 & 0.003 & $\begin{array}{c}0.40 \\
(0.21-0.73)\end{array}$ & 0.58 & $\begin{array}{c}1.78 \\
(0.23-13.51)\end{array}$ \\
\hline School [304] & $19(6)$ & $70(23)$ & $42(14)$ & $67(22)$ & $106(35)$ & & 0.006 & $\begin{array}{c}0.41 \\
(0.22-0.77)\end{array}$ & 0.29 & $\begin{array}{c}3.00 \\
(0.39-22.73)\end{array}$ \\
\hline Illiterate ${ }^{* *}[46]$ & $1(2)$ & $9(20)$ & $0(0)$ & $10(22)$ & $26(57)$ & & & & & \\
\hline \multicolumn{11}{|l|}{$\begin{array}{l}\text { Perception of } \\
\text { Current Practice }\end{array}$} \\
\hline Males [420] & $37(9)$ & $104(25)$ & $119(28)$ & $87(21)$ & $73(17)$ & $<0.001$ & 0.93 & 1.02 & $\begin{array}{c}< \\
0.001\end{array}$ & 0.38 \\
\hline Females** [426] & $87(20)$ & $146(34)$ & $66(16)$ & $54(13)$ & $73(17)$ & & & $(0.71-1.45)$ & & $(0.25-0.57)$ \\
\hline Saudis [758] & $116(15)$ & $230(30)$ & $161(21)$ & $125(17)$ & $126(17)$ & 0.02 & 0.15 & 0.68 & 0.12 & 1.81 \\
\hline$\underline{\text { Non-Saudi Arabs** [88] }}$ & $8(9)$ & $20(23)$ & $24(27)$ & $16(18)$ & $20(23)$ & & & $(0.40-1.16)$ & & $(0.85-3.84)$ \\
\hline Patients [304] & $41(14)$ & $88(29)$ & $60(20)$ & $59(19)$ & $56(18)$ & 0.20 & 0.50 & 1.13 & 0.47 & 0.86 \\
\hline Healthy** [542] & $83(15)$ & $162(30)$ & $125(23)$ & $82(15)$ & $90(17)$ & & & $(0.79-1.64)$ & & $(0.58-1.29)$ \\
\hline$\geq$ College [524] & $66(13)$ & $167(32)$ & $136(26)$ & $73(14)$ & $82(16)$ & 0.004 & 0.83 & $\begin{array}{c}1.11 \\
(0.42-2.95)\end{array}$ & 0.01 & $\begin{array}{c}0.31 \\
(0.17-0.78)\end{array}$ \\
\hline School [286] & $48(17)$ & $66(23)$ & $49(17)$ & $64(22)$ & $59(21)$ & & 0.38 & $\begin{array}{c}1.56 \\
(0.58-4.20)\end{array}$ & 0.09 & $\begin{array}{c}0.50 \\
(0.23-1.12)\end{array}$ \\
\hline Illiterate** [35] & $10(29)$ & $16(46)$ & $0(0)$ & $4(11)$ & $5(14)$ & & & & & \\
\hline
\end{tabular}

*"Don't disclose", and disclose when there is a "major harm", "moderate harm", "minor harm", or "near miss" correspond, respectively, to statements 1 to 5 in Table 1(a). Data indicate the number (\%) of respondents who chose the corresponding statement. Numbers between [.] represent the number of responses from participants with the indicated characteristic. ${ }^{\mathrm{a}}$ Mann-Whitney test or Kruskal-Wallis test (for educational status). ${ }^{\mathrm{b}}$ Mantel-Haenszel common odds ratio estimate.

** Reference group in the Mantel-Haenszel estimate. Percentages may not add up to 100 due to rounding.

We used a forward stepwise logistic regression model that included age, gender (female as reference group), nationality (Non-Saudi Arabs as a reference group), health status (healthy as a reference group), and educational level (illiterates as reference group). For predicting preference of disclosure of near miss ME (vs. other preferences), only age, gender, and health status remained in the model as significant predictors (OR 1.02 (1.01 to 1.04) per year, $\mathrm{P}=0.008 ; 0.45$ (0.34 to 0.60$), \mathrm{P}<0.001$; and 0.60 (0.44 to 0.82$), \mathrm{P}=0.001$, respectively). For predicting preference of no-disclosure of ME (vs. other preferences), only age and gender were significant predictors (OR 0.96 (0.92 to 0.99$)$ per year, $\mathrm{P}=0.02$ and 3.95 (1.86 to 8.39 ), $\mathrm{P}<0.001$, respectively). There were no significant predictors of the perception that in current practice patients are informed of near miss ME; and only gender predicted the perception that patients are not informed of ME (OR 0.38 (0.25 to 0.57 ), P < $0.001)$. The logistic regression model also showed that gender predicted preference of ME disclosure by atfault-physician and the perception that in current practice ME are disclosed by at-fault-physician (OR 0.49 (0.35 to 0.69 ), $\mathrm{P}<0.001$ and 0.45 (0.33 to 0.61$), \mathrm{P}<$ 0.001 , respectively). 
Table 6 Who to disclose Medical Error According to Public Preference and Perception of Current Practice per Demographic Characteristics

\begin{tabular}{|c|c|c|c|c|c|c|c|c|c|}
\hline & \multicolumn{6}{|c|}{ Statement* } & \multirow[t]{2}{*}{$\begin{array}{c}\text { Overall } \\
\mathrm{P}^{\mathrm{a}}\end{array}$} & \multicolumn{2}{|c|}{$\begin{array}{c}\text { At-fault- } \\
\text { physician vs. } \\
\text { other choices }\end{array}$} \\
\hline & $\begin{array}{l}\text { Any } \\
\text { employee }\end{array}$ & $\begin{array}{l}\text { Any } \\
\text { physician }\end{array}$ & $\begin{array}{l}\text { At-fault } \\
\text { physician }\end{array}$ & $\begin{array}{l}\text { Manager of At-fault- } \\
\text { physician }\end{array}$ & $\begin{array}{l}\text { Medical } \\
\text { director }\end{array}$ & $\begin{array}{l}\text { Chief executive } \\
\text { director }\end{array}$ & & $P$ & $\begin{array}{l}\text { OR }(95 \% \\
\text { Cl) }\end{array}$ \\
\hline \multicolumn{10}{|l|}{ Personal Preference } \\
\hline Males [399] & $7(2)$ & $65(16)$ & $191(48)$ & 77 (19) & $36(9)$ & $23(6)$ & 0.04 & $\begin{array}{c}< \\
0.001\end{array}$ & 0.40 \\
\hline Females** [468] & $9(2)$ & $40(9)$ & $327(70)$ & $56(12)$ & $18(4)$ & $18(4)$ & & & $(0.30-0.52)$ \\
\hline Saudis [778] & $14(2)$ & $92(12)$ & $468(60)$ & $117(15)$ & $53(7)$ & $34(4)$ & 0.74 & 0.50 & 1.18 \\
\hline Non-Saudi Arabs** [89] & $2(2)$ & $13(15)$ & $50(56)$ & $16(18)$ & $1(1)$ & $7(8)$ & & & $(0.76-1.83)$ \\
\hline Patients [327] & $8(2)$ & $44(14)$ & $202(62)$ & $48(15)$ & $16(5)$ & $9(3)$ & 0.02 & 0.34 & 1.15 \\
\hline Healthy** [540] & $8(2)$ & $61(11)$ & $316(59)$ & $85(16)$ & $38(7)$ & $32(6)$ & & & $(0.87-1.52)$ \\
\hline$\geq$ College [534] & $11(2)$ & $68(13)$ & $310(58)$ & $95(18)$ & $32(6)$ & $18(3)$ & 0.10 & 0.13 & $\begin{array}{c}0.61 \\
(0.32-1.16)\end{array}$ \\
\hline School [286] & $3(1)$ & $31(11)$ & $176(62)$ & $34(12)$ & $21(7)$ & $21(7)$ & & 0.30 & $\begin{array}{c}0.70 \\
(0.36-1.37)\end{array}$ \\
\hline Illiterate $^{* *}[46]$ & $2(4)$ & $6(13)$ & $32(70)$ & $4(9)$ & $1(2)$ & $1(2)$ & & & \\
\hline \multicolumn{10}{|l|}{$\begin{array}{l}\text { Perception of Current } \\
\text { Practice }\end{array}$} \\
\hline Males [405) & $54(13)$ & $118(29)$ & $104(26)$ & $76(19)$ & $27(7)$ & $26(6)$ & 0.50 & $\begin{array}{c}< \\
0.001\end{array}$ & 0.45 \\
\hline Females** [353] & $20(6)$ & $120(34)$ & $154(43)$ & $23(7)$ & $16(5)$ & $20(6)$ & & & $(0.33-0.61)$ \\
\hline Saudis [674] & $66(10)$ & $215(32)$ & $229(34)$ & $87(13)$ & $40(6)$ & $37(6)$ & 0.32 & 0.92 & 0.98 \\
\hline Non-Saudi Arabs ${ }^{* *}[84]$ & $8(10)$ & $23(27)$ & $29(35)$ & $12(14)$ & $3(4)$ & $9(11)$ & & & $(0.61-1.57)$ \\
\hline Patients [270] & $14(5)$ & $91(34)$ & $102(38)$ & $38(14)$ & $15(6)$ & $10(4)$ & 0.48 & 0.11 & 1.29 \\
\hline Healthy $^{* *}[488]$ & $60(12)$ & $147(30)$ & $156(32)$ & $61(13)$ & $28(6)$ & $36(7)$ & & & $(0.95-1.76)$ \\
\hline$\geq$ College [478] & $58(12)$ & $158(33)$ & $154(32)$ & $61(13)$ & $25(5)$ & $22(5)$ & 0.002 & 0.42 & $\begin{array}{c}0.60 \\
(0.27-1.36)\end{array}$ \\
\hline School [254] & $15(6)$ & $70(28)$ & $93(37)$ & $36(14)$ & $17(7)$ & $23(9)$ & & 0.47 & $\begin{array}{c}0.74 \\
(0.32-1.69)\end{array}$ \\
\hline Illiterate ${ }^{* *}[25]$ & $1(4)$ & $10(40)$ & $11(44)$ & $1(4)$ & $1(4)$ & $1(4)$ & & & \\
\hline
\end{tabular}

*"Any employee", "any physician", "at-fault-physician", "manager of at-fault-physician", "medical director", and "chief executive director" correspond, respectively, to statements 1 to 6 in Table 1(b). Data indicate the number (\%) of respondents who chose the corresponding statement. Numbers between [.] represent the number of responses from participants with the indicated characteristic. ${ }^{a}$ Mann-Whitney test or Kruskal-Wallis test (for educational status). ${ }^{b}$ Mantel-Haenszel common odds ratio estimate.

** Reference group in the Mantel-Haenszel estimate. Percentages may not add up to 100 due to rounding.

\section{Discussion}

The aim of this study was to survey public views on disclosure of ME to patients in the outpatient setting at a tertiary healthcare center in Riyadh, Saudi Arabia. We studied a convenient sample of 902 adult Arabs and examined three perspectives (preference, perception of norm, and perception of current practice) on two topics (which ME to disclose and who to disclose ME). The study sample had a mean (SD) age of 33.9 (10) year, $47 \%$ males, $90 \%$ Saudis, $37 \%$ patients with chronic illness $(63 \%$ were independent healthy patients' companions), $49 \%$ employed, and $61 \%$ with college or higher education. The strengths of the study include a large sample size, a high response rate, simultaneous examination of preference, perception of norm, and perception of current practice, specifically addressing near miss $\mathrm{ME}$, and being the first in the Islamic/Arab culture. Its weaknesses include that it was performed in a single institution and thus the results may not be generalizable, and that it did not compare people who were or were not actually exposed to ME. We found that: 1) there is a considerable diversity in preferences and perceptions of norm and current practice among respondents both regarding which ME to disclose and by whom, 2) distributions of preference and perception of norm were similar but significantly different from the distribution of perception of current practice, 3) most respondents preferred to be informed of ME and by atfault-physician, and 4) one third of respondents preferred to be informed of near miss ME, with a higher 
percentage among females, older, and healthy individuals.

The observed diversity in preferences suggests that a one-fits-all policy on ME disclosure may results in patient's dissatisfaction. The diversity in perceptions of norm may be due to an absence of a norm or that the norm is not well known to the public. KFSH\&RC has been accredited by the Joint Commission on International Accreditations since November 2000, and ME disclosure is included in its policy. However, the Rules of Implementation for Regulation of the Practice of Medicine and Dentistry that were promulgated by the Saudi Ministry of Health in January 1990 [34] and the more recent Ethics of Medical Profession released by the Saudi Commission of Health Specialists are silent on the issue [35]. From Islamic teachings point of view, it is expected that a mistake or error is disclosed, an apology is given, and forgiveness is sought. Prophet Muhammad has taught, "Whoever has oppressed another person concerning his reputation or anything else, he should beg him to forgive him before the Day of Resurrection when there will be no money (to compensate for wrong deeds), but if he has good deeds, those good deeds will be taken from him according to his oppression which he has done, and if he has no good deeds, the sins of the oppressed person will be loaded on him."[36]. This would be understood to imply that the Islamic norm is to disclose, sincerely apologize, and rectify all harmful $\mathrm{ME}$, even if associated with only a minor harm. Interestingly, in a physicians' survey, respondents who agreed that forgiveness is important for their spiritual or religious belief were more likely to disclose a hypothetical error resulting in a minor harm [37].

Our failure to find significant differences between preferences and perceptions of norm may be due to respondents' inability to differentiate between the two. This is not likely because they were relatively highly educated (61\% had college or higher education) and the two questions were presented at the same time. Alternatively, it may reflect a rather norm-desiring culture that seeks harmony between motives (preference) and reasons (perception of norm) or a social desirability bias (a low inclination to express a preference that is different from the perceived norm).

We found that the distribution of perception of current practice regarding which ME to disclose is shifted to the left (less demanding) compared to the distributions of preference and perception of norm. Relatively, more disclosure was preferred and perceived as norm, indicating a degree of disagreement and dissatisfaction of the public with current practice. Respondents were asked about their perception of ME disclosure practice at the KFSHRC, a leading hospital in the area. A larger disclosure gap would be expected for other hospitals.
Although patients may be mistaken in their perception of current practice, such gap has been well documented in previous studies under different settings, and has been attributed to the difference between patients' and physicians' declared preferences and between physicians' preference and what they actually do $[5,10,37,38]$. Another potential contributor to this gap is respondents' inclusion of unanticipated outcomes among ME. In a study in the rural areas in USA, $41 \%$ of the ME perceived by 172 respondents involved only unanticipated outcome [39]. Patients may have a broader definition of ME that includes poor service quality, significant delay in treatment, non-preventable adverse events, and deficient interpersonal skills [5]. A community survey in Oman found that only $78 \%$ of participants believed they knew what was meant by ME [40]. The discrepancy between preference and perception of current practice in our study was mainly in extreme choices (no-disclosure and disclosure of near miss $\mathrm{ME}$ ) and more pronounced among females and people with lower education. This may indicate more dissatisfaction with current practice in these two groups. A previous study did not reveal an association between preference for ME disclosure and gender or education level [14].

Consistent with previous studies [5,10,13,14,17], we found that overall $95.5 \%$ of respondents preferred to be informed of ME. It is not known if this consistently expressed preference would change during an acute illness $[10,41]$. Interestingly, compared to healthy individuals, patients in our study were more likely to prefer disclosure of harmful ME and less likely to prefer the more extreme choices (no-disclosure and disclosure of near miss ME).

Current regulations are silent regarding disclosure of near miss $\mathrm{ME}$ and while some authorities recommend disclosure [21-24], others disagree [[2,25], and [26]]. An important finding of our study is that $35.5 \%$ of respondents preferred to be informed of near miss ME. This is a much smaller percentage than the $88-92 \%$ reported in previous studies [15,27]. Interestingly, our study also showed that $30.4 \%$ of respondents perceived that the norm is to disclose near miss ME. Do patients have the ethical right to be informed of near miss ME? Although reporting of near miss $\mathrm{ME}$ is an important quality improvement measure [1,3] and public disclosure of near miss ME (in aggregate) can be considered part of informed consent for future patients, it is arguable that one can defend disclosure of near miss ME to the patient involved based on the Rights approach or RuleUtilitarian approach (looks at the consequences of having everyone follow a particular rule and calculates the overall utility of accepting or rejecting the rule) to ethics [42]. On one hand, one can argue that as an extension 
of the principle of autonomy, patients have the right to know of near miss ME because it may help them make more informed healthcare choices, alert them to which error they should watch for, and create an opportunity for them to be part of quality improvement efforts [5]. It would also reassure them that the systems to prevent ME from reaching them were working [5], educate them about the uncertainty of medicine, promote faith in the patient/physician relationship, provide a check point in case the healthcare system fails to improve, and allow gaining absolution from truth telling and confession on part of physicians [42]. Two third of physicians believed that disclosing a mistake to the patient would help alleviate their feeling of guilt [37] and 74\% of whoever disclosed a serious error experienced a relief after disclosure [45]. On the other hand, disclosure of near miss ME may raise in the patient feelings of anger, "useless" dissatisfaction, and undue suspicion. Physicians may have uncertainties about patient's response to disclosure, whether an error actually occurred, and how to disclose it, and may feel a sense of shame - I was what was wrong [43] and helplessness (losing control over the situation), especially in a culture that focuses on individual responsibility rather than system improvement. Further, such disclosure may be impractical for physicians [19] and may put them at a conflict between their others-regarding posture and self-regarding posture [42] as they fear loss of reputation and malpractice litigation [37]. In this regard, a recent welcome legal development in some countries is a medical apology law that protects physicians who apology to patients from admission of medical liability [44]. Furthermore, near miss disclosure is not practiced outside the medical field, for example, people are not informed of human errors in maintaining or flying airplanes if harm doesn't occur, although this also involves human lives. Requiring physicians to be more virtuous than the society as a whole may not be fair or reasonable [42]. Thus disclosure of near miss ME may be better addressed through the Virtue approach to ethics (promotes situational appreciation since virtue is an activity in accordance with reason), ethical relativism (morality is culture- and circumstance-dependent), and Act-Utilitarianism (looks at the consequences of each individual act and calculate utility each time the act is performed). This is consistent with the recommendations of the American Society for Reproductive Medicine [26]. In our study, females, older peoples, and healthy individuals were significantly more likely to indicate preference for disclosure of near miss ME. It is not clear why some people are more likely to be interested in information that may be disappointing and have no practical use. It could be due to a higher desire for information in general, relative lack of other competing information, or a higher degree of autonomy. This has not been addressed in previous studies. There were no significant differences among the various demographic groups in current practice perception of disclosure of near miss ME.

Some believe that ME disclosure must be conducted as mush as possible by those originally involved in patient care $[10,11,22,29]$ and that physicians should take responsibility for their own errors by personally disclosing and apologizing for them [46]. Others have advised that the healthcare provider "who last touched the patient" should not be part of the disclosure team, at least initially, because he/she may be lacking the required communication skills and experiencing emotional turmoil $[21,28]$. Thirty four percent of our respondents ( $43 \%$ of females and $26 \%$ of males) have the perception that under current practice ME are disclosed by at-fault-physician. A US national survey showed that only $30 \%$ of the respondents who experienced ME were reportedly informed by the involved healthcare provider [47]. Almost $60 \%$ of respondents (70\% of females and $48 \%$ of males) in the current study preferred and perceived it as norm to be informed of ME by at-fault-physician. This may indicate that they want an apology rather than a disciplinary action or just information and that they see $\mathrm{ME}$ as a physician responsibility rather than an organizational/systems issue. Understanding cultural expectations such as truth telling and forgiveness can provide insight into patients needs [46]. Just as secular Western societies continue to be influenced by Judo-Christian norms concerning social ethics [46], Arabic and Islamic societies are still influenced by Islamic social ethics which shares many foundational values with Judaism and Christianity [48]. Forgiveness and truth telling are praised in several verses of Quran, for example: "Be quick in the race for forgiveness from your Lord, and for a Garden whose width is that (of the whole) of the heavens and of the earth, prepared for the righteous. Those who spend (freely), whether in prosperity, or in adversity; who restrain anger, and pardon (all) men; for Allah loves those who do good." (Chapter 3 , verses 133,134$)$, "O ye who believe! stand out firmly for justice, as witnesses to Allah, even as against yourselves, or your parents, or your kin, and whether it be (against) rich or poor: for Allah can best protect both. Follow not the lusts (of your hearts), lest ye swerve, and if ye distort (justice) or decline to do justice, verily Allah is well-acquainted with all that ye do."(Chapter 4, verse 135) [49]. Fulfilling patients' cultural expectations may help patients forgive physicians and physicians reach self-forgiveness; a systems approach may not apply here since the patient/physician relationship is perceived to be present between individuals, not between a person and a "system" [46]. An apology for ME implies admission of fault and expression of regret for the action and 
sympathy for the results, but does not necessarily contain an acknowledgment of responsibility [44]. At a cognitive level, apology allows patients to take the perspective of the "at-fault-physician", having a more positive perception of his/her character and recognizing that the circumstances may have played a role. At an affective level, it allows patients to appreciate that the "at-fault-physician" is also suffering [44]. The type of apology, whether an apology of regret/sympathy or an apology of responsibility, may not be as important in soothing patient's anger and suspicion as the perceived sincerity $[10,50]$, and this can be best conveyed by the at-fault-physician.

\section{Conclusions}

In the setting of outpatient clinics at a tertiary care hospital in Saudi Arabia, we found that: 1) There is a considerable diversity in preferences and perceptions of norm and current practice regarding which ME to disclose and by whom, which may indicate that a one-fitsall policy for ME disclosure may result in patients' dissatisfaction and that there is a need for more public education on patients' rights regarding ME disclosure. 2) Distributions of preference and perception of norm were similar, suggesting a rather norm-desiring culture, but significantly different from the distribution of perception of current practice, suggesting a perceived gap between preference/norm and current practice, especially in females and in individuals with lower education level. 3) Most respondents preferred to be informed of ME, consistent with previous studies in other cultures, and to be informed by at-fault physician, indicating that they are looking for an apology rather than a disciplinary action or just information. Finally, only one third of respondents preferred to be informed of near miss ME, which is much lower than what was reported in previous studies, with even a lower percentage among males, young, and sick individuals.

\section{Additional material}

Additional file 1: Study questionnaires. The six study questionnaires.

\begin{abstract}
Acknowledgements
The study was funded by a grant from The King Faisal Specialist Hospital \& Research Center (KFSH\&RC) to MMH. KFSH\&RC had no role in study design; in the collection, analysis, and interpretation of data; in the writing of the manuscript; or in the decision to submit the manuscript for publication.

\section{Authors' contributions}

MMH conceived of the study, participated in study design, performed statistical analysis, participated in literature review, and wrote the manuscript. SA participated in data collection, literature review, and statistical analysis. MA participated in study design, data collection, and literature review. All authors read and approved the final manuscript.
\end{abstract}

\section{Competing interests}

The authors declare that they have no competing interests.

Received: 23 July 2010 Accepted: 18 October 2010

Published: 18 October 2010

\section{References}

1. Kohn LT, Corrigan JM, Donaldson MS: To err is human: building a safer health system. A report of the Committee on Health Care in America, Institute of Medicine Washington, DC: National Academy Press 2000.

2. Murphy JG, McEvoy MT: Revealing medical errors to your patients. Chest 2008, 133:1064-1065.

3. Barach P, Small SD: Reporting and preventing medical mishaps: lessons from non-medical near miss reporting systems. BM J 2000, 320:759-63.

4. Calvert JF Jr, Hollander-Rodriguez J, Atlas M, Johnson KE: Clinical inquiries. What are the repercussions of disclosing a medical error? J Fam Pract 2008, 57(2):124-5.

5. Gallagher TH, Waterman AD, Ebers AG, Fraser VJ, Levinson W: Patients' and physicians' attitudes regarding the disclosure of medical errors. JAMA 2003, 289(8):1001-7.

6. Edwin AK: Non-disclosure of medical errors an egregious violation of ethical principles. Ghana Med J 2009, 43(1):34-9.

7. Joint Commission on Accreditation of Healthcare Organization: Comprehensive Accreditation Manual for Hospitals: The Official Handbook. Illinois: JCAHO 2004.

8. Sorensen RS, Ledema R, Piper D, Manias E, Williams A, Tuckett A: Health care professionals' views of implementing a policy of open disclosure of errors. J Health Ser Res Policy 2008, 13(4):227-232.

9. Kalra J, Massey KL, Mulla A: Disclosure of medical error: policies and practice. JR Soc Med 2005, 98(7):307-9.

10. Gallagher $\mathrm{TH}$, Lucas $\mathrm{MH}$ : Should we disclose harmful medical errors to patients? if so, how? JCOM 2005, 12(5):253-259.

11. Open disclosure: a review of the literature (2008). Edited by: Allan A, Munro B [http://www.psychology.ecu.edu.au/staff/documents/allanA/ 86 Allan_OD_Literature Review.pdf], Accessed July 2010.

12. Apologies in the healing process: The apology act 2008. The registered nurses' association of Ontario. [http://www.rnao.org/Storage/53/ 4741_RNAO_Bill_108_Apology_Act_submission_-_Feb_2009.pdf], Accessed July 2010 ..

13. Hobgood C, Tamayo-Sarver JH, Elms A, Weiner B: Parental preferences for error disclosure, reporting, and legal action after medical error in the care of their children. Pediatrics 2005, 116(6):1276-86.

14. Hobgood C, Tamayo-Sarver JH, Weiner B: Patient race/ethnicity, age, gender and education are not related to preference for or response to disclosure. Qual Saf Health Care 2008, 17:65-70.

15. Witman AB, Park DM, Hardin SB: How do patients want physicians to handle mistakes? A survey of internal medicine patients in an academic setting. Arch Intern Med 1996, 156:2565-9.

16. Hingorani M, Wong T, Vafidis G: Patients' and doctors' attitudes to amount of information given after unintended injury during treatment. cross sectional, questionnaire survey BMJ 1999, 318:640-641.

17. Mazor KM, Simon SR, Yood RA, Martinson BC, Gunter MJ, Reed GW, Gurwitz JH: Health plan members' views about disclosure of medical errors. Ann Intern Med 2004, 140(6):409-18.

18. Mazor KM, Reed GW, Yood RA, Fischer MA, Baril J, Gurwitz JH: Disclosure of medical errors: what factors influence how patients respond? J Gen Intern Med 2006, 21(7):704-10.

19. Cantor MD: Telling patients the truth: a systems approach to disclosing adverse events. Qual Saf Health Care 2002, 11:7-8.

20. Levinson W, Gallagher TH: Disclosing medical errors to patients: a status report in 2007. CMAJ 2007, 177(3):265-7.

21. Liang BAA: system for medical error disclosure. Qual Saf HealthCare 2002 11:64-8.

22. Wu AW: Handling hospital errors: Is disclosure the best defense? Ann Intern Med 1999, 131(12):970-972.

23. Kalantri SP: Medical errors and ethics. Indian J Anaesth 2003, 47(3):174-175.

24. Hébert PC, Levin AV, Robertson G: Bioethics for clinicians: 23. Disclosure of medical error. CMAJ 2001, 164(4):509-13.

25. Lo B: Resolving ethical dilemmas: a guide for clinicians. Baltimore: Williams \& Wilkins 1995. 
26. The Ethics Committee of the American Society for Reproductive Medicine: Disclosure of medical errors involving gametes and embryos. Fertility and Sterility 2006, 86(3):513-515.

27. Hobgood C, Peck CR, Gilbert B, Chappell K, Zou B: Medical errors-what and when: what do patients want to know? Acad Emerg Med 2002, 9(11):1156-61.

28. Kraman SS, Hamm G: Risk management: extreme honesty may be the best policy. Ann Intern Med 1999, 131:963-7.

29. UPMC Presbyterian Policy and Procedure Manual: Guidelines for disclosure and discussion of conditions and events with patients, families and guardians. Kennedy Ethics Inst J 2001, 11:165-8.

30. Gillon R: Ethics needs principles - four can encompass the rest - and respect for autonomy should be "first among equals". J Med Ethics 2003, 29:307-312.

31. Campbell A: The virtues (and vices) of the four principles. J Med Ethic 2003, 29:292-296.

32. Macklin R: Applying the four principles. J Med Ethics 2003, 29:275-280.

33. Joffe S, Manocchia M, weeks J, Cleary P: What do patients value in their hospital care? An empirical perspective on autonomy centered bioethics. J Med Ethics 2003, 29:103-108.

34. Kingdom of Saudi Arabia, Ministry of Health, Forensic Medicine: Rules of Implementation for Regulations of the Practice of Medicine and Dentistry., No 288/17/L dated 26/6/1410H.

35. Saudi Council for Health Specialists: Ethics of the Medical Profession. [http://english.scfhs.org.sa/Book/EN-scfhs_2007_p1.pdf], Accessed July 2010.

36. Sahih Bukhari:Edited by: Muhsin Khan 3(43):629[http://www.usc.edu/ schools/college/crcc/engagement/resources/texts/muslim/hadith/bukhari/ 043.sbt.html], Accessed July 2010..

37. Kaldjian LC, Jones EW, Wu BJ, Forman-Hoffman VL, Levi BH, Rosenthal GE: Disclosing medical errors to patients: attitudes and practices of physicians and trainees. J Gen Intern Med 2007, 22(7):988-96, Epub 2007 May 1.

38. Loren DJ, Klein EJ, Garbutt J, Krauss MJ, Fraser V, Dunagan WC, Brownstein DR, Gallagher TH: Medical error disclosure among pediatricians: choosing carefully what we might say to parents. Arch Pediatr Adolesc Med 2008, 162(10):922-7.

39. Van Vorst RF, Araya-Guerra R, Felzien M, Fernald D, Elder N, Duclos C, Westfall JM: Rural community members' perceptions of harm from medical mistakes: a High Plains Research Network (HPRN) Study. J Am Board Fam Med 2007, 20(2):135-43.

40. Al-Mandhari AS, Al-Shafaee MA, Al-Azri MH, Al-Zakwani IS, Khan M, AlWaily AM, Rizvi S: A survey of community members' perceptions of medical errors in Oman. BMC Med Ethics 2008, 29(9):13.

41. Cohen JR: Future research on disclosure of medical errors. Ann Inter Med 2004, 141(6):481.

42. Mavroudis C, Mavroudis CD, Naunheim KS, Sade RM: Should surgical errors always be disclosed to the patient? Ann Thorac Surg 2005, 80(2):399-408

43. Gawande A: Complications: A Surgeon's Notes on an Imperfect Science. New York, NY: Metropolitan Books 2002.

44. Allan A: Apology in civil law: a psyco-legal perspective. Psychiatry, Psychology and Law 2007, 14(1):5-16.

45. Gallagher TH, Waterman AD, Garbutt JM, Kapp JM, Chan DK, Dunagan WC, Faser VJ, Levinson W: US and Canadian physicians' attitudes and experiences regarding disclosing errors to patients. Arch Intern Med 2006, 166:1605-11.

46. Berlinger N, Wu AW: Subtracting insult from injury: addressing cultural expectations in the disclosure of medical error. J Med Ethics 2005, 31(2):106-8.

47. Blendon RJ, DesRoches CM, Brodie $M$, et al: Views of practicing physicians and public on medical error. N Eng J Med 2003, 347:1933-40.

48. Daar SAbdallah, Khitamy A: Bioethics for clinicians: 21. Islamic bioethics CMAJ 2001, 164(1):60-63.

49. The Meanings of The Holy Qur'an by Abdullah Yusufali. [http://www. islam101.com/quran/yusufAli/index.htm], Accessed July 2010..

50. Liebman CB, Hyman CS: A mediation skills model to manage disclosure of errors and adverse events to patients. Health Affairs 2004, 23(4):22-32.

\section{Pre-publication history}

The pre-publication history for this paper can be accessed here:

http://www.biomedcentral.com/1472-6939/11/17/prepub doi:10.1186/1472-6939-11-17

Cite this article as: Hammami et al:: Which medical error to disclose to patients and by whom? Public preference and perceptions of norm and current practice. BMC Medical Ethics 2010 11:17.

\section{Submit your next manuscript to BioMed Central and take full advantage of:}

- Convenient online submission

- Thorough peer review

- No space constraints or color figure charges

- Immediate publication on acceptance

- Inclusion in PubMed, CAS, Scopus and Google Scholar

- Research which is freely available for redistribution

Submit your manuscript at www.biomedcentral.com/submit
C) Biomed Central 